\title{
Performance and Risk Assessment of Subsurface Barriers for Single-Shell Tank Waste Retrieval
}

G. D. Bazinet

J. M. Cruse

K. L. Hampsten

Westinghouse Hanford Company

R. L. Treat

Foster Wheeler Environmental Corp.

Date Published

February 1995

To Be Presented at

American Society of Mechanical Engineers

Waste Management '95

Tucson, Arizona

February 26, 1995

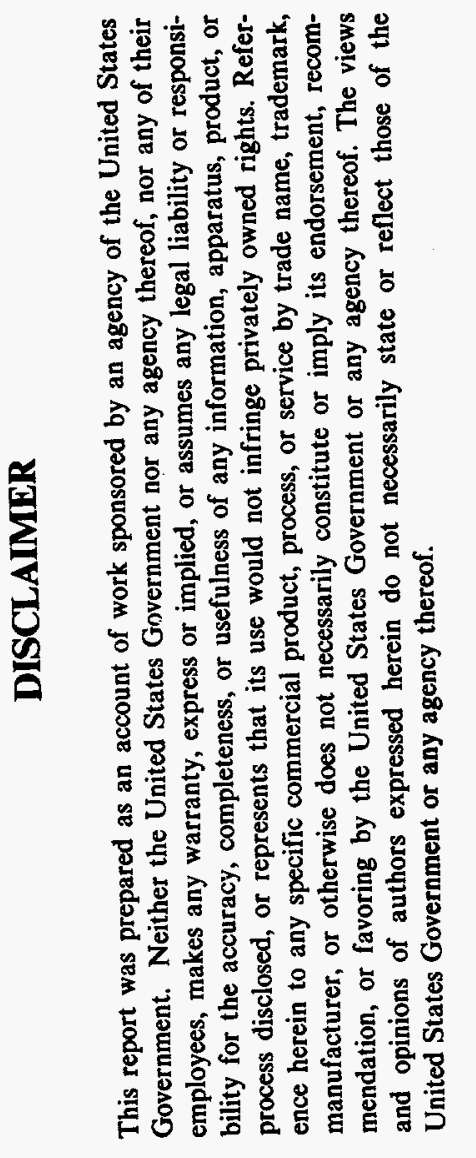

Prepared for the U.S. Department of Energy Office of Environmental Restoration and Waste Management

(2) Westinghouse $\begin{aligned} & \text { P.O. Box } 1970 \\ & \text { Hanford Company }\end{aligned}$

Hanford Operations and Engineering Contractor for the U.S. Department of Energy under Contract DE-AC06-87RL10930

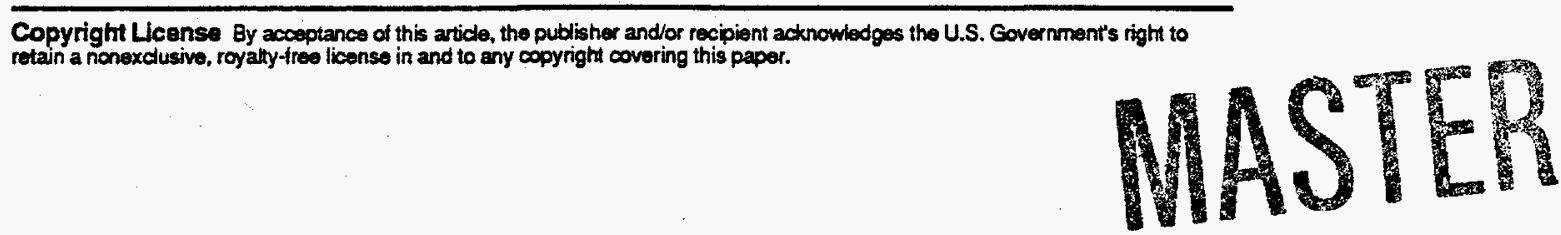

Approved for Public Release 


\section{DISCLAIMER}

Portions of this document may be illegible in electronic image products. Images are produced from the best available original document. 


\title{
PERFORMANCE AND RISK ASSESSMENT OF SUBSURFACE BARRIERS FOR SINGLE-SHELL TANK WASTE RETRIEVAL
}

Gerald D. Bazinet, Jonathan M. Cruse, and Kenneth L. Hampsten, Westinghouse Hanford Company

Russell L. Treat, Foster Wheeler Environmental, Corporation

\begin{abstract}
Subsurface barriers are among various alternatives under evaluation to mitigate the threat of leakage from the Hanford Site's 149 single-shell high-level radioactive waste tanks. The Tank Waste Remediation System (TWRS) division of Westinghouse Hanford Company is conducting this evaluation of subsurface barriers and other alternatives, focusing on risk and cost as performance measures.
\end{abstract}

A number of alternative retrieval/closure approaches were evaluated in terms of risks (carcinogenic and toxicological) to a postulated maximally exposed individual. In addition, worker and accident risks were evaluated and factors developed for each alternative on a relative basis. The work performed to date indicates the use of subsurface barriers may potentially reduce public risk by limiting contamination of groundwater below the Hanford Site; however, the cost in terms of actual funding and in elevated worker risk is significant. The analyses also assume certain performance levels for technologies that have not been demonstrated in field conditions similar to Hanford Site tank farms.

The evaluations summarized herein are being used to support a decision by representatives of the U.S. Department of Energy, Richland Operations Office, the Washington State Department of Ecology (Ecology), and the U.S. Environmental Protection Agency (EPA) regarding potential further development of subsurface barrier technology.

\section{BACKGROUND}

The Hanford Site's 149 single-shell tanks (SSTs) currently store approximately 140 million liters (37 million gallons) of high-level radioactive liquid waste. Objectives for environmental cleanup of the Hanford Site include retrieving, treating, and disposing of the SST waste in an acceptable manner. The TWRS program is responsible for achieving these objectives in accordance with the Tri-Party Agreement, U.S. Department of Energy (DOE) orders, and state and federal regulations applicable to environmental clean-up.

Historically, tank wastes have been released to the ground from leaks from SSTs, and associated transfer lines, and other miscellaneous spills. Sixty-seven SSTs are assumed to have leaked a total volume of approximately 2,271 to $3,407 \mathrm{~m}^{3}(600,000$ to $900,000 \mathrm{gal})$. Several studies have indicated that the contaminants present in this volume of leakage could cause violation of groundwater quality standards, once the contaminants migrate through the vadose zone to the groundwater.

The Hanford SST tank farms were constructed from 1943 to 1964. Retrieval of waste from the SSTs is currently scheduled for a 15-year processing campaign beginning in 2003 and ending in 2018. One tank, C-106, is planned for retrieval in 1997 to provide a demonstration of retrieval technology. Accordingly, the SSTs will be 60 to 75 years old at the initiation of retrieval, depending on the sequence for individual tanks.

Hydraulic sluicing is the primary approach currently envisioned for retrieval of the SST waste. The sluicing operations will typically add some level of working liquid to the tank to mobilize the solidified salt cakes and sludges. The design life of the tanks has expired, and the integrity of the tank containment boundaries is in 
question. The age of the tanks and the fact that leakage paths exist in a number of tanks already strongly indicates that sluicing retrieval operations will likely cause additional leakage of tank waste to the surrounding soil unless preventive actions can be taken.

The concerns of environmental impact due to migration of the contaminants that have already leaked from the tanks and the potential for additional leakage during retrieval have driven the initiative to evaluate alternatives for leakage mitigation. The TWRS program is investigating a number of options to mitigate past and potential future leakage from the SSTs. The evaluation and decision processes are reflected in the following Tri-Party Agreement milestones:

M-45-07A Complete Evaluation of Subsurface Barrier Feasibility (September 1994)

Complete a feasibility study of barriers to accomplish the following:

1. Estimate the potential environmental impact of waste storage and retrieval activities without the application of barriers.

2. Establish functional requirements of barriers to minimize the impact associated with the waste storage and retrieval activities.

3. Evaluate the application of existing subsurface barrier technologies to meet functional requirements of barriers and the potential reduction in environmental impacts from the application of barriers to SST waste storage and retrieval activities.

M-45-07B Reach Decision on Whether to Proceed with Demonstration (January 1995)

Based on the results of the subsurface barrier feasibility study, Ecology, EPA, and DOE will make a decision on whether to proceed with a sub-scale demonstration. If the decision is negative, then interim milestone $M-45-07$ will be considered complete.

\section{EMERGING TECHNOLOGIES}

A number of subsurface barrier development projects are active in the DOE Office of Technology Development (EM-50) Program under the Crosscutting Technology, Plumes, and Landfills Focus Areas. Industry has made a number of proposals to DOE-Headquarters and the field in technologies such as a heated, continuous air barrier and a cryogenic soil freezing system. The continuous air barrier concept is designed to stop/prevent leaks by crystallizing salt in the soil pores by evaporation, thereby sealing the soil from further leaks. The soil freezing system is designed to create a basin of ice beneath the tank, thereby providing a mechanism for capturing any leaked waste. The Underground Storage Tank - Integrated Demonstration tasks conducted in fiscal years 1992 and 1993 (TTPs RL421210 and CH321203) began work on an instrumented test facility and evaluated several barrier systems. The proponents of a number of these subsurface barrier systems, including the air barrier, frozen soil basin, and a technology that provides a physical barrier adjacent to and beneath the tank, claim that they are "ready for demonstration."

The Plumes Focus Area is supporting ongoing research and development of materials that may serve as effective solid barriers around tanks and other waste sites. These materials include organic polymers, cementitious grouts, and paraffins. While several of these materials appear promising, methods of injecting the materials into the soil to effect a seal around tanks are largely untested. Several fiscal year 1995 projects will focus on deployment of subsurface barriers below waste sites. One example is called the horizontal soil saw, a device that is pulled below the waste site by cables previously placed in directionally drilled holes. As it moves through the soil, a rotating "grouting bar" both cuts the soil and injects barrier-forming grout or other material. 
The Hanford Site's TWRS Program has conducted several studies and workshops to evaluate the potential application of subsurface barriers at the tank farms. Based on this work, three subsurface barrier concepts have emerged for consideration: (1) injected or infused material barriers, (2) cryogenic barriers, and (3) desiccant barriers. These barrier types may be installed in two configurations: close-coupled (against the tank structure) and stand-off (with a soil layer between the tank(s) and barrier).

\section{PERFORMANCE AND RISK ASSESSMENT}

The overall objective of the feasibility evaluation was to analyze a logical set of subsurface barrier technologies in terms of overall system performance, as measured primarily by public risk reduction, worker and accident risks, and cost.

\section{Integrated Alternatives}

To compare the various alternatives on an even basis, integrated alternatives were constructed by assuming a retrieval method, the use or nonuse of subsurface barriers for leakage mitigation, and several closure methods. A total of fourteen alternative retrieval/leakage mitigation/closure approaches were evaluated. Fig. 1 provides a flow chart that depicts the integrated alternatives.

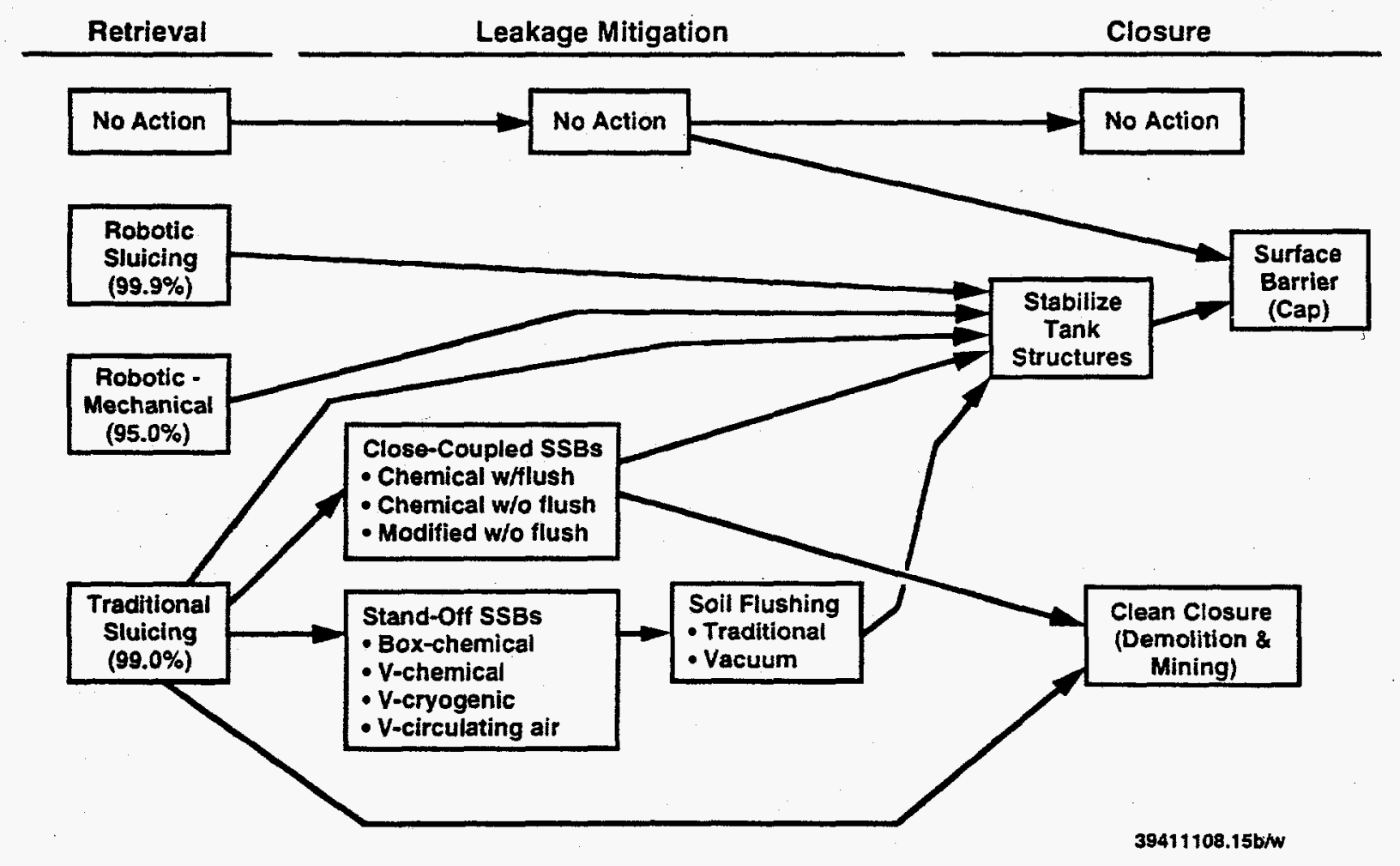

Fig. 1. Subsurface Barrier Integrated Alternatives. 
The evaluation process required that a number of assumptions be made regarding performance of the alternative concepts. Key assumptions included the performance of the retrieval system in terms of the percentage of waste removed from the tanks, and the effective recharge rate of the tank farm and vadose zone soil system (with or without a surface barrier) following retrieval.

\section{Public Risk}

The public risk assessment was performed as a two-step process: the first step estimated the inventories of contaminants of concern in the various sources, then estimated the rates and durations of the releases to the vadose zone, and the second step modeled the transport through the vadose zone and aquifer to obtain potential exposure to a hypothetical maximally exposed individual (MEI).

The analyses assumed a hypothetical tank farm consisting of 12 tanks with a capacity of $3,785 \mathrm{~m}^{3}$ (1 million gallons) each. The waste composition was assumed equal to the average of the 149 SSTs. Soil chemistry and lithology representative of overall Hanford Site properties were assumed. The SST waste inventory includes more than 150 chemicals and radionuclides; however, a relatively small subset of the constituents are sufficiently toxic and mobile that they can produce a significant public risk impact.

Eight constituents of concern were retained in the analyses as the dominant contributors to public risk.

The dominant sources in terms of contribution to the public (MED) risk values were residual waste in the tanks following retrieval and the contamination resulting from old and new leaks. However, other sources resulted in substantive contributions; other sources analyzed included: waste trapped between steel and concrete, residual waste that diffused or advected into the concrete, residual waste that diffused or advected into barrier material (if applicable).

The Multimedia Environmental Pollutant Assessment System code was used to model the contaminant transport through the vadose zone to the aquifer and to compute risk factors to the MEI resulting from use of the groundwater. Cancer risk factors were calculated for exposure to carcinogens, and hazard index (HI) factors were calculated for exposure to noncarcinogens. The receptor was assumed to have a 70-year lifetime. Exposure pathways included drinking water ingestion, crop ingestion, and animal product ingestion.

The transport and risk calculations were run over a 30,000-year postoperational period. The duration of this model was needed to show the magnitude and time of the peaks in risk to the MEI. Fig. 2 and 3 show the carcinogenic and $\mathrm{HI}$ curves for all alternatives.

\section{Worker and Accident Risks}

Potential risks to worker health and safety were evaluated by further defining the alternatives in terms of individual technology options. The work force needed to support each option was estimated on a life-cycle basis and included technology readiness, capital, operating and maintenance, and decontamination and decommissioning. The risk factors were formulated to address exposure to radioactive and hazardous materials and physical hazards associated with the activities. Table I shows the results of the evaluation.

\section{Cost/Cost Benefit}

Cost estimates were developed for each of the alternatives based on recent engineering studies and other data. The cost estimates were based on the life cycle elements as described in the worker safety analysis. The cost benefit for each alternative was based on risk reduction versus cost. Table II presents costs as total pet present worth (TNPW). The relative risk value is the peak carcinogenic risk calculated for the postoperational phase (Fig. 2). Cost benefit (based on carcinogenic risk) is calculated using Equation 1.

$$
C-B_{\text {riak }}=\left[\left(\text { Risk }_{i} / \text { Risk }_{n}\right)-1\right] / T N P W
$$




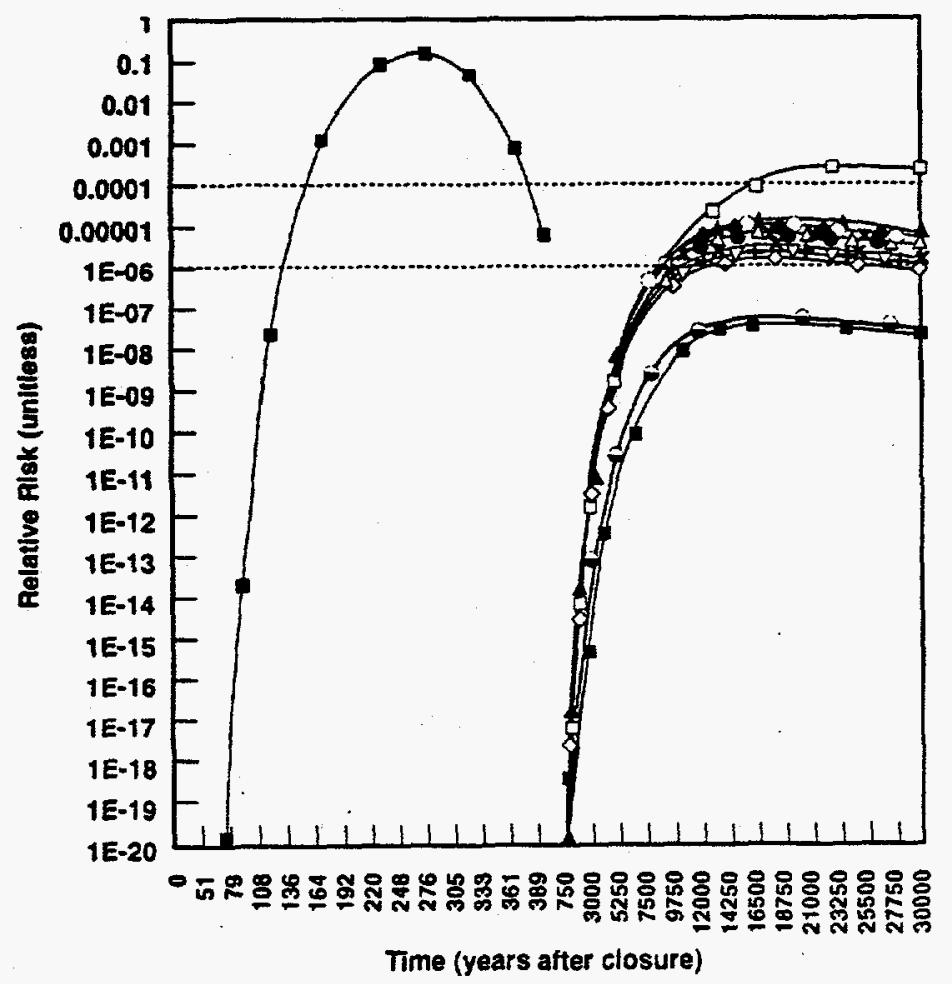

- No Action

a Surfece Barrier

- Traditional Sluicing

- Robotic Sluicing

- Mechanical Mining

$\Delta$ Close-Coupled (C-C) w/ Flush

- C-C wio Soll Flushing

$c$ Mod C-C w/o Flush

$x$ Box-Shaped Chemlcal

* V-Shaped Chemical

+ V-Shaped Freeze Wall

$\nabla$ Circulating Air

- Clean Closure w/o Barrier

- Clean Closure w/Barrier

39811108.24

Fig. 2. Summary of Carcinogenic Risks for all Alternatives.

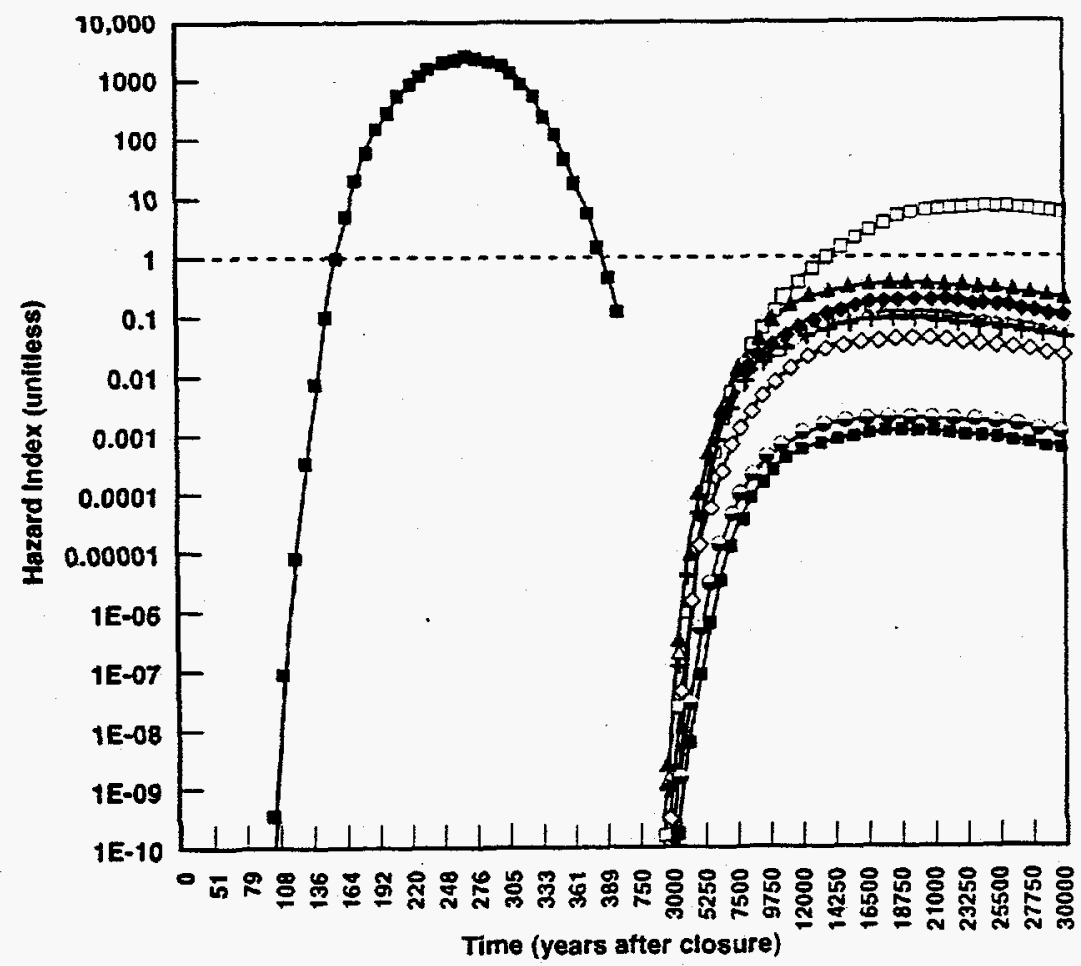

- No Action

- Surface Barrier

- Traditional Sluicing

- Robotic Sluicing

- Mechanlcal Mining

$\Delta$ Close-Coupled (C-C) w/ Fiush

- C-C w/o Soll Flushing

o Mod C-C w / o Flush

$x$ Box-Shaped Chemical

$x$ V-Shaped Chemical

+ V-Shaped Freeze Wall

$\nabla$ Circulating Air

- Clean Closure w/o Barrier

- Clean Closure w/ Barrier

Fig. 3. Summary of Toxicant Hazard Risks for all Alternatives. 
TABLE I. Worker Safety Analysis Results.

\begin{tabular}{|l|c|c|c|}
\hline \multicolumn{1}{|c|}{ Alternative Name } & $\begin{array}{c}\text { Relative } \\
\text { Fatalities }\end{array}$ & $\begin{array}{c}\text { Relative } \\
\text { Injuries }\end{array}$ & $\begin{array}{c}\text { Relative } \\
\text { Cancer Risk }\end{array}$ \\
\hline 1. No Action & 0.0 & 0.0 & 0.0 \\
2. Surface Barrier Only & 0.08 & 0.08 & 0.02 \\
3. Traditional Sluicing & 1.0 & 1.0 & 1.0 \\
4. Robotic/Long-Reach Arm & 5.1 & 5.0 & 7.0 \\
5. Mechanical Retrieval & 4.8 & 4.6 & 7.0 \\
6. Close-Coupled Chemical with Flushing & 5.1 & 4.3 & 4.9 \\
7. Close-Coupled Chemical w/o Flushing & 2.7 & 2.2 & 2.2 \\
8. Modified Close-Coupled w/o Flushing & 2.4 & 2.0 & 1.8 \\
9. Box Shaped Chemical & 4.4 & 4.6 & 3.2 \\
10. V-Shaped Chemical & 5.3 & 5.4 & 3.8 \\
11. V-Shaped Freeze Wall & 4.9 & 5.0 & 4.1 \\
12. Circulating Air Barrier & 4.4 & 4.3 & 4.6 \\
13. Clean Close & 13.3 & 9.6 & 15.4 \\
14. Clean Close & 13.9 & 10.0 & 15.7 \\
\hline
\end{tabular}

TABLE II. Cost and Cost Benefit Summary for all Alternatives.

\begin{tabular}{|l|r|c|c|}
\hline \multicolumn{1}{|c|}{ Alternative Name } & $\begin{array}{c}\text { Cost } \\
\text { TNPW }\end{array}$ & $\begin{array}{c}\text { Relative } \\
\text { Risk }\end{array}$ & $\begin{array}{c}\text { Cost } \\
\text { Benefit }\end{array}$ \\
\hline 1. No Action & 0 & $1.5 \mathrm{E}-1$ & N/A \\
2. Surface Barrier Only & 8 & $3.7 \mathrm{E}-4$ & 51 \\
3. Traditional Sluicing & 110 & $1.1 \mathrm{E}-5$ & 124 \\
4. Robotic/Long-Reach Arm & 423 & $2.5 \mathrm{E}-6$ & 142 \\
5. Mechanical Retrieval & 360 & $2.1 \mathrm{E}-5$ & 20 \\
6. Close-Coupled Chemical with Flushing & 629 & $5.2 \mathrm{E}-6$ & 46 \\
7. Close-Coupled Chemical w/o Flushing & 302 & $7.0 \mathrm{E}-6$ & 71 \\
8. Modified Close-Coupled w/o Flushing & 259 & $8.0 \mathrm{E}-6$ & 72 \\
9. Box Shaped Chemical & 681 & $4.9 \mathrm{E}-6$ & 45 \\
10. V-Shaped Chemical & 792 & $4.9 \mathrm{E}-6$ & 39 \\
11. V-Shaped Freeze Wall & 786 & $4.8 \mathrm{E}-6$ & 40 \\
12. Circulating Air Barrier & 586 & $5.1 \mathrm{E}-6$ & 50 \\
13. Clean Close & 1,629 & $1.1 \mathrm{E}-7$ & 92 \\
14. Clean Close & 1,576 & $6.3 \mathrm{E}-8$ & 92 \\
\hline
\end{tabular}

TNPW $=$ total net present worth.

The cost-benefit factors calculated based on hazard index are numerically different; however, the relative changes between alternatives would lead to the same conclusions as the values based on carcinogenic risk shown above. To provide clearer resolution among the various technologies, an incremental risk reduction value was calculated using Equation 2:

$$
\text { Incremental } \mathrm{C}-\mathrm{B}_{\text {risk }}=\frac{\left(\text { Risk }_{\mathrm{n}} / \text { Risk }_{\mathrm{m}}\right)-1}{\mathrm{TNPW}_{\mathrm{m}}-\mathrm{TNPW}_{\mathrm{n}}}
$$


Table III presents the incremental risk values based on implementation of individual technologies.

TABLE III. Incremental Cost-Effectiveness of Selected Actions.

\begin{tabular}{|l|c|c|}
\hline \multicolumn{1}{|c|}{ Actions } & \multicolumn{2}{c|}{ Cost-Effectiveness } \\
\cline { 2 - 3 } & Overall & Incremental \\
\hline Use traditional sluicing and grout tank voids - no surface barrier & 0.3 & 0.3 \\
Add a surface barrier (Alt. 3) & 124 & 54 \\
Add a close-coupled chemical barrier with flushing (Alt. 6) & 46 & 0.0021 \\
Add a close-coupled chemical barrier without flushing (Alt. 7) & 71 & 0.0030 \\
Add a modified close-coupled chemical barrier w/o flushing (Alt. 8) & 72 & 0.0025 \\
Add a box-shaped chemical barrier with flushing (Alt. 9) & 45 & 0.0022 \\
Add a v-shaped chemical barrier with flushing (Alt. 10) & 39 & 0.0018 \\
Add a v-shaped freeze wall barrier with flushing (Alt. 11) & 40 & 0.0019 \\
Add a circulating air barrier with flushing (Alt. 12) & 50 & 0.0024 \\
Add a stand-off barrier without flushing (modified Alt. 9-12) & 0 & 0 \\
Clean Close with close-coupled barrier (Alt. 14) & 92 & -0.14 \\
\hline
\end{tabular}

\section{Sensitivity of Results}

A five-phase analysis was performed to examine the sensitivity of the results to the following: variability in performance of subsurface barriers, variability in geology and waste composition, variability in release rate of constituents, the affects of high leakage and variation in performance of the surface barrier and soil flushing, and variability in vadose zone water potential due to leakage. The analyses concluded the results are highly sensitive to the assumptions regarding performance of the protective surface barrier to limit the affects of recharge to the tanks and vadose zone soil system. The results are also highly sensitive to the assumption that the tanks will be reasonably effective in containing the waste inventory during sluicing operations. Other variations had little affect on results.

\section{CONCLUSIONS}

The results of the feasibility evaluation support the following conclusions:

- Taking no action would result in risks approximately three orders of magnitude higher than the assumed upper limit $\left(10^{-4}\right)$ of the target risk range.

- Taking no action other than capping a tank farm with a surface barrier capable of limiting recharge to $0.05 \mathrm{~cm} /$ year (0.02 in./year) may result in acceptable risks for some tanks, but only if collapse of the tank domes could be prevented.

- The use of either traditional sluicing (assumed capable of achieving $99 \%$ tank waste retrieval), robotic sluicing ( $99.9 \%$ retrieval), or mechanical retrieval $(95 \%$ retrieval), in combination with stabilizing the structure of emptied tanks and using a surface barrier, appears potentially capable of attaining the target risk range for most tanks.

- The use of any of the subsurface barrier concepts (chemical, freeze wall, and circulating air in close-coupled and standoff configurations) in general applications to tank farms would result in a relatively small incremental reduction in the risk level achievable using baseline technologies. (Baseline technologies include traditional sluicing, emptied-tank stabilization, and surface barriers.) 
- Uncertainty in the performance of subsurface barriers is high, but because the impact of subsurface barriers on risk and cost-effectiveness is very low, even best-case assumptions of subsurface barrier performance have a relatively small effect on improving overall risk and cost-effectiveness of SST disposal options.

- Stand-off barriers offer no benefit in terms of reducing public risk unless soil flushing or excavation is used in conjunction. The requirement for soil flushing in the stand-off barrier alternatives results in a large cost impact.

- The use of a close-coupled barrier to support clean-closure activities may be cost-effective in comparison to the clean-closure alternative without a barrier because it would limit the volume and reduce the cost of contaminated soil requiring excavation and treatment, while reducing risk.

- Except for the clean-closure application, cost-effectiveness of subsurface barrier technologies is essentially equal and relatively low. The cost-effectiveness of the subsurface barriers, calculated by the method most favorable to subsurface barriers, is about 0.0001 times that of surface barriers, and 0.01 times that of the set of baseline technologies.

- The retrieval of all tank waste, including tank structures and contaminated soil to effect cleanclosure, would likely result in bettering the public risk range. The landfill created to contain washed, retrieved soil and debris from the tank farm would represent a new, but relatively small source of risk.

- The clean-closure alternatives would be about as cost-effective as other tank waste retrieval alternatives assuming that all recovered contaminants of environmental concern would be destroyed or treated and disposed offsite in a federal repository, and assuming that benefit can be represented as a ratio of initial risk to achieved risk. If benefit is represented by the difference in these risks, the cost-benefit is two to eight times lower than for the other retrieval alternatives.

- Worker risks of the baseline alternative are 2 to 5 times lower than subsurface barrier alternatives and about 10 to 15 times lower than the clean-closure alternatives.

- Functional requirements have been established in Functions and Requirements for Single-Shell Tank Leakage Mitigation (1). All functional requirements potentially can be satisfied using any of the subsurface barrier options evaluated.

These conclusions are based on the ability of subsurface barriers to reduce risk and improve cost-effectiveness in general-use applications to tank farms. A broader set of values beside risk and cost-effectiveness should be considered. Conclusions presented here may be modified as a result.

The risk and cost factors and the methods of their calculation used in the evaluation process were developed using the most recent information available, given the available resources and schedule. The evaluation team considers the approach taken to be correct and defensible. However, there is no set standard for this kind of evaluation and decision process. This paper is a very cursory summary of the work performed. Individuals with an interest in reviewing the detailed information may contact the authors to obtain the supporting documentation $(2,3)$. 


\section{REFERENCES}

1. J. M. CRUSE, Functions and Requirements for Single-Shell Tank Leakage Mitigation, WHC-SD-WM-FRD-019, Rev. 0, Westinghouse Hanford Company, Richland, Washington (1994).

2. WHC, Feasibility Study of Tank Leakage Mitigation Using Subsurface Barriers, WHC-SD-WM-ES-300, Rev. 0, Westinghouse Hanford Company, Richland, Washington (1994).

3. WHC, Tri-Party Agreement Milestone M-45-07A - Complete Evaluation of Subsurface Barrier Feasibility (Summary Report), WHC-SD-WM-ES-311, Rev. 0, Westinghouse Hanford Company, Richland, Washington (1994). 


\section{DISTRIBUTION}

\section{Number of copies}

OFFSITE

2

Foster Wheeler Environmental, Corp. 1981 Snyder Road, Suite 3

Richland, WA 99352

R. L. Treat

B. B. Peters

1

WM Symposia, Inc.

245 S. Plumer, Suite 19

Tucson, AZ 85719

\section{ONSITE}

1

U.S. Department of Energy,

Richland Operations Office

$\begin{array}{ll}\text { W. W. Wrzesinski } & \text { R3-74 }\end{array}$

2

Pacific Northwest Laboratory

M. E. Peterson

K2-47

J. D. Vick

K7-94

11

Westinghouse Hanford Company

H. Babad

57-30

G. D. Bazinet

S4-53

J. M. Cruse (3)

L5-63

R. C. Eschenbaum

$\mathrm{N} 1-45$

L. A. Fort

S4-54

G. A. Meyer

S4-54

J. P. Mullally

S4-53

Information Release

Administration

L8-07

Document Processing and

Distribution

L8-15 